\title{
Metastasis of renal cell carcinoma to the thyroid gland after 9years:A case report and review of the literature
}

\begin{abstract}
Introduction: Cancer metastasis to the thyroid from a distant site is rare. A significant proportion of all secondary thyroid tumors are due to metastasis from clear cell renal carcinoma (CCRC). Here, we report a case of thyroid metastasis from a clear renal cell carcinoma several years after the diagnosis.

Case presentation: 71years old male with history of CCRC treated with partial left nephrectomy 9years previously, presented with weight loss and given his history of previous CRCC, further workup with CT thorax, abdomen and pelvis revealed presence of thyroid nodules requiring further assessment. Ultrasound assessment of the thyroid, showed a large, solid and isoechoic right lobe nodule. Fine needle aspiration cytology was non diagnostic on two occasions, total thyroidectomy and histopathological assessment showed evidence of thyroid metastasis from CCRC.

Conclusions: Secondary tumors in the thyroid gland are difficult to diagnose without cytology or histopathologic examination. Therefore, preoperative diagnosis of secondary thyroid neoplasm could be a challenge and requires detailed knowledge of the patient history. History of clear renal cell carcinoma in this case was important and has helped to think about thyroid metastasis before having the tissue diagnosis.
\end{abstract}

Keywords: metastasis, renal cell carcinoma, thyroid cancer
Volume 7 Issue 6 - 2019

\author{
Fedail M,' El Zubier E, ${ }^{2}$ Toulaymat M $^{3}$ \\ 'Department of Endocrinology, Dr Sulaiman Al Habib Hospital, \\ Saudi Arabia \\ 2Department of Nephrology, Dr Sulaiman Al Habib Hospital, \\ Saudi Arabia \\ ${ }^{3}$ Department of Histopathology, Dr Sulaiman Al Habib Hospital, \\ Saudi Arabia
}

Correspondence: Fedail M, Department of Endocrinology, Dr Sulaiman Al Habib Hospital, Olaya, Riyadh, Saudi Arabia, Email moawiafedail200@yahoo.com

Received: October 14, 2019 | Published: November 05, 2019

\section{Introduction}

The majority of the thyroid tumors are primary and these include papillary, follicular, medullary and anaplastic thyroid carcinomas. Clinically detectable metastatic thyroid cancer is rare, about $1-2.4 \%$ of all malignant thyroid nodules. ${ }^{1}$ CCRC is the most frequent primary tumor metastasizing to the thyroid. It represents $3 \%$ of all adult malignancies. ${ }^{2}$ Autopsy data showed that thyroid metastasis range from $1.9 \%$ to $24.2 \%$, with the most common primary sites of cancer skin, lung, and breast. ${ }^{3,4}$ In the clinically recognized metastases to the thyroid gland, CCRC represents more than half of the primary cancer. ${ }^{5}$ The presentation and behavior of thyroid metastasis from renal cancer are variable. Here, we report a very unusual case of metastatic CCRC to the thyroid gland in a patient who had undergone right partial nephrectomy for CCRC 9years previously.

\section{Case presentation}

A 71-year old man referred for further thyroid assessment in May 2016, following incidental finding of a relatively large thyroid nodule on CT scan of the thorax, abdomen and pelvis done for further assessment of weight loss in the context of his known previous history of renal cell carcinoma. He was euthyroid clinically and biochemically. There, was no dysphagia or dyspnea. His medical history includes type 2 diabetes diagnosed 1998, hyperlipidemia, hypertension, albuminuria and history of partial left nephrectomy for renal cell carcinoma 9years previously (2007). Physical examination was unremarkable.

In May 2016, CT thorax abdomen and pelvis for assessment of weight loss revealed no evidence of renal cancer recurrence, but there was a heterogenous right thyroid lobe lesion measuring $2.3 \mathrm{~cm} \times 1.8 \mathrm{~cm}$. Subsequent ultrasound assessment of this thyroid lesion showed a right lobe solid and isoechoic nodule with few cystic areas measuring $3.5 \times 2.74 \mathrm{~cm}$. There were other small nodules less than $0.5 \mathrm{~cm}$ in the left lobe. Fine needle aspiration (FNA) and cytology of the right lobe nodule in June 2016 was suboptimal, repeat FNA and cytology around 2weeks later was of borderline adequacy and the findings were non-specific. He proceeded for total thyroidectomy in July 2016, the histology revealed clear cell neoplasm with morphic features in keeping with metastatic renal cell carcinoma (Figure $1 \& 2$ ). Immunohistochemical stain showed that the tumor was negative for thyroid transcription factor -1 (TTF-1) (Figure 3) and positive for CD10 (Figure 4). He was commenced on thyroid hormone replacement following thyroidectomy. Postoperative staging with positron emission tomography (PET) scan was unremarkable. ${ }^{6}$

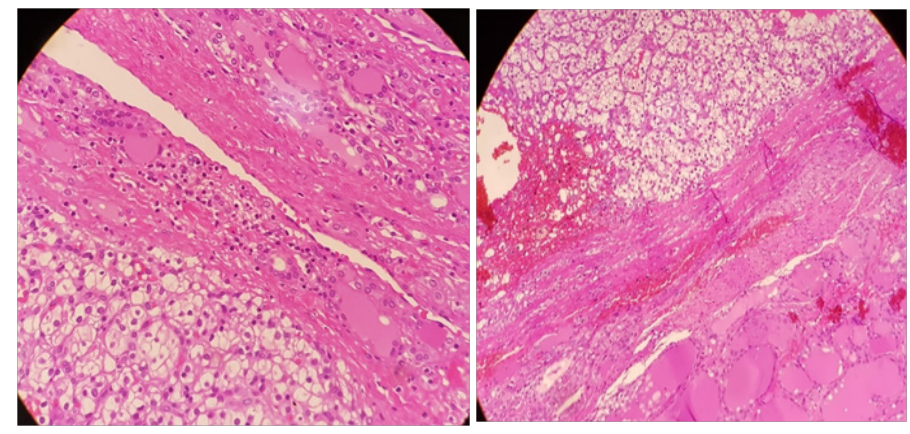

Figure I \&2 Show the interface between normal thyroid tissue and the tumor. 


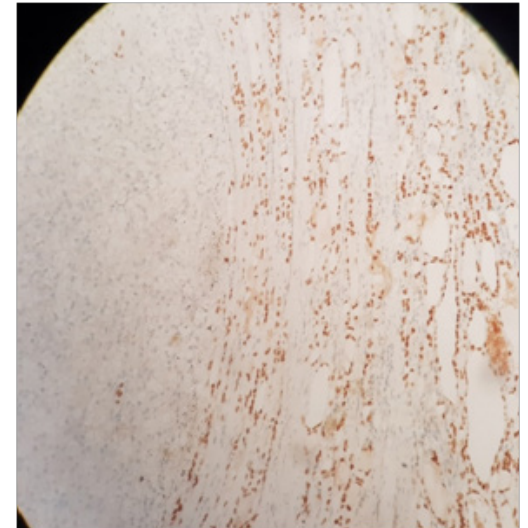

Figure 3 The immunohistochemical stain, thyroid transcription factor- $I$ is positive for follicular adenoma and negative in metastatic renal cell carcinoma.

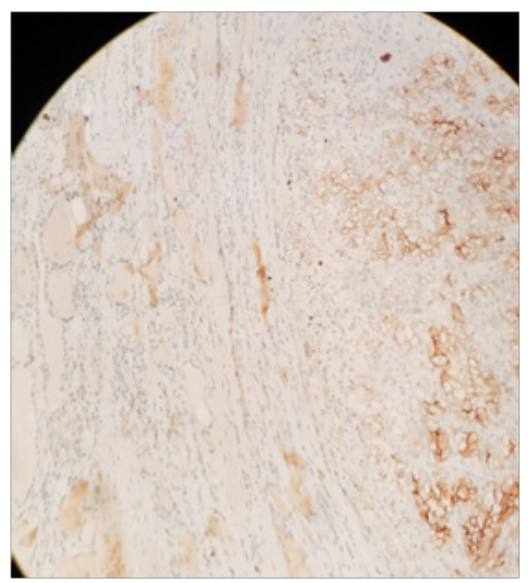

Figure 4 Immunohistochemical stain; CDIO is positive in metastatic renal cell carcinoma and negative in follicular proliferation.

\section{Discussion}

The most common original site from which metastasis to the thyroid gland occurs is reported to be the kidney in a case series. ${ }^{7,8}$ Renal cell cancer originating from the renal tubular epithelium, and the clear cell type is the most common variant. ${ }^{9}$ Histo-pathologically, clear cell carcinoma shows polygonal cells with clear cytoplasm, distinct cell membranes, small compact eccentric nuclei, and a rich vascular network. The likelihood of primary renal cell carcinoma to spread to regional lymph nodes and various organ site is well known. CCRC constitutes approximately $85 \%$ of all primary renal tumors; its incidence increases with age. ${ }^{10,11}$

When a previous history of nephrectomy for renal cell carcinoma is recognized in such a patient, ultrasound examination as well as cytology is effective and helpful in order to make the diagnosis preoperatively. Preoperative recognition of a previous history of renal cell carcinoma in a patient must be the most important clue for the correct diagnosis of the disease, which many publications have emphasized. ${ }^{7,8,12}$ The history and findings in our case support these recommendations. CCRC recurrence after nephrectomy is highly variable, presenting with metastasis ranging from a few months to several years after the initial diagnosis. ${ }^{10,11}$ Some authors have reported that the thyroid is a common site of metastasis because it is rich in blood supply, they suggested that the thyroid gland would be more brone to metastasis when affected by goiter, neoplasms, or thyroiditis due to some metabolic changes that reduce it's oxygen and iodine content. ${ }^{13}$ On the other hand, other authors have found no difference in the rate of metastasis in abnormal thyroid glands compared to normal thyroid glands ${ }^{13}$. When cytological results are not conclusive. The diagnosis of metastatic CCRC is made with histopathological examination after thyroidectomy. Immunohistochemistry can be helpful for the differential diagnosis, with metastatic cells of CCRC positive for $\mathrm{CD} 10$ and vimentin and negative for thyroglobulin, calcitonin, and TTF- $1 .{ }^{4}$ In our patient, knowing that he has previous history of CCRC, has prompted us to reach a definitive diagnosis regarding the nature of his thyroid nodule. Therefore, after 2nondiagnostic FNA and cytology, we had proceeded to thyroidectomy and histopathological examination. The diagnosis was then confirmed by immunohistochemistry.

\section{Conclusions}

Thyroid metastasis needs to be considered in patients with a thyroid nodule and a history of clear cell renal carcinoma. It is challenging to differentiate between primary and secondary tumors preoperatively. Immunohistochemistry is an important tool for assessment of the histopathological specimens of patients with suspicious thyroid nodules. Metastatic cells are usually negative for thyroglobulin, calcitonin, TTF-1 and positive for CD10 and vimentin.

\section{Acknowledgments}

None.

\section{Conflicts of interest}

The author declares that there is no conflict of interest.

\section{Funding}

None.

\section{References}

1. Calzolari F, Sartori PV, Talarico C, et al. Surgical treatment of intrathyroid metastases: Preliminary results of a multicenter study. Anticancer Res. 2008;28(5B):2885-2888.

2. Ryska A, Cap J. Tumor-to-tumor metastasis of renal cell carcinoma into oncocytic carcinoma of the thyroid: report of a case and review of the literature. Pathol Res Pract. 2003;199(2):101-106.

3. Nakhjavani MK, Gharib H, Goellner JR, et al. Metastasis to the thyroid gland. A report of 43cases. Cancer. 1997;79(3):574-578.

4. Fadare O, Parkash V, Fiedler PN, et al. Tumor-to-tumor metastasis to a thyroid follicular adenoma as the initial presentation of a colonic adenocarcinoma. Pathol Int. 2005;55(9):574-579.

5. Bohn OL, de las Casas LE, Leon ME. Tumor-to-tumor metastasis: renal cell carcinoma metastatic to papillary carcinoma of thyroid. Report of a case and review of the literature. Head Neck Pathol. 2009;3(4):327-330.

6. Wolf G, Aigner RM, Humer-Fuchs U, et al. Metastasis of a renal cell carcinoma in a microfollicular adenoma of the thyroid gland. Acta Med Austriaca. 2002;29(4):141-142.

7. Chung AY, Tran TB, Brumund KT, et al. Metastases to the thyroid: a review of the literature from the last decade. Thyroid. 2012;22(3):258268.

8. Sindoni A, Rizzo M, Tuccari G, et al. Thyroid metastases from renal cell carcinoma: review of the literature. Scientific World Journal. 2010;10:590-602. 
9. Russo P. Renal cell carcinoma: presentation, staging, and surgical treatment. Semin Oncol. 2000;27(2):160-176.

10. Koul H, Huh JS, Rove KO, et al. Molecular aspects of renal cell carcinoma: a review. Am J Cancer Res. 2011;1(2):240-254.

11. Jemal A, Siegel R, Xu J, et al. Cancer statistics, 2010. CA Cancer J Clin. 2010;60(5):270-300.
12. Duggal NM, Horattas MC. Metastatic renal cell carcinoma to the thyroid gland. Endocr Pract. 2008;14(8):1040-1046.

13. Heffess CS, Wenig BM, Thompson LD. Metastatic renal cell carcinoma to the thyroid gland: a clinicopathologic study of 36cases. Cancer. 2002;95(9):1869-1878. 